\title{
Influence of Dietary Protein Levels on Hepatic Cysteine Dioxygenase Activity in Rainbow Trout
}

\author{
Masahito Yokoyama, Miho Udagawa, and Jun-ichi Nakazoe \\ National Research Institute of Fisheries Science, Ministry of Agriculture, Forestry, and Fisheries, Fukuura, Kanazawa, \\ Yokohama 236, Japan
}

(Received November 16, 1993)

\begin{abstract}
Fingerling rainbow trout were fed experimental diets having different protein levels for 10 days to determine the sulfur amino acid metabolism involving taurine biosynthesis in fish. Either egg white albumin or casein was employed as a sole dietary protein source. Maximum body weight gain was obtained at about $40 \%$ crude protein level in both dietary groups. However, further increase in dietary protein did not improve the growth rate of the fish. Specific activity of the hepatic cysteine dioxygenase (CDO) [EC 1.12.11.20] in the fish fed the egg white albumin diets increased exponentially as dietary protein level increased, whereas no clear effect on enzyme activity was noted in the casein dietary group. Judging from the difference in the sulfur amino acid contents between egg white albumin and casein, the hepatic CDO activity of rainbow trout seems to be closely related to dietary sulfur amino acid levels rather than protein levels. The accumulation of cystathionine in the fish fed a high egg white albumin diet suggests that the capacity of the transsulfuration pathway in rainbow trout is limited.
\end{abstract}

Key words: rainbow trout, sulfur amino acid, cysteine dioxygenase, transsulfuration, cysteine

Cysteine dioxygenase (CDO) [EC 1.13.11.20] catalyzes the oxygenation of L-cysteine to form L-cysteine sulfinate. In mammals, L-cysteine sulfinate is a key intermediate product in the catabolic pathway to form pyruvate and sulfate, and in taurine biosynthesis pathway from L-cysteine. ${ }^{1,2)}$ Thus, this enzyme is considered to play an important role in regulating the sulfur amino acid metabolism in mammals. ${ }^{3)}$ Hosokawa et al. ${ }^{4)}$ demonstrated in rats that the activity of CDO in the liver could be used as a sensitive indicator of the nutritive value of dietary protein source. Although the sulfur amino acids such as methionine and cystine are essential nutrients for fish, information on the sulfur amino acid metabolism in fish is scarce.

Previously, we observed that hepatic CDO activity was enhanced also in rainbow trout by supplementing the $40 \%$ casein diet with $1 \%$ methionine or cystine. ${ }^{5)}$ More studies are needed to clarify whether the sulfur amino acid metabolism in fish is controlled by dietary protein level and/or sulfur amino acid levels. This study therefore focused on the CDO activity in the tissues, and feeding experiments on rainbow trout were conducted using diets containing various levels of either egg white albumin or casein as the sole source of dietary protein, because these have markedly different amino acid compositions. We also attempted to clarify the transsulfuration pathway and cysteine catabolism involving taurine biosynthesis in rainbow trout.

\section{Materials and Methods}

\section{Experimental Diets}

The compositions of the experimental diets are given in Table 1. Either egg white albumin which was denatured with hot ethanol under reflux for six hours or a commercially available vitamin-free casein was employed

Table 1. Composition of experimental diets

\begin{tabular}{|c|c|c|c|c|c|c|c|c|c|c|c|c|}
\hline & \multicolumn{12}{|c|}{ Diet number } \\
\hline & 1 & 2 & 3 & 4 & 5 & 6 & 7 & 8 & 9 & 10 & 11 & 12 \\
\hline \multicolumn{13}{|l|}{ Ingredient $(\%)$} \\
\hline Egg white albumin & 10 & 20 & 30 & 40 & 50 & 60 & - & - & - & - & - & - \\
\hline Casein & - & - & - & - & - & - & 10 & 20 & 30 & 40 & 50 & 60 \\
\hline$\alpha-S t a r c h$ & 10 & 10 & 10 & 10 & 10 & 10 & 10 & 10 & 10 & 10 & 10 & 10 \\
\hline Dextrin & 53 & 43 & 33 & 23 & 13 & 3 & 53 & 43 & 33 & 23 & 13 & 3 \\
\hline Lipid*1 & 10 & 10 & 10 & 10 & 10 & 10 & 10 & 10 & 10 & 10 & 10 & 10 \\
\hline Cellulose & 10 & 10 & 10 & 10 & 10 & 10 & 10 & 10 & 10 & 10 & 10 & 10 \\
\hline Mineral mixture ${ }^{* 2}$ & 5 & 5 & 5 & 5 & 5 & 5 & 5 & 5 & 5 & 5 & 5 & 5 \\
\hline Vitamin mixture ${ }^{* 3}$ & 2 & 2 & 2 & 2 & 2 & 2 & 2 & 2 & 2 & 2 & 2 & 2 \\
\hline Crude protein (\%) & 8.6 & 17.2 & 25.7 & 34.6 & 42.6 & 51.2 & 8.7 & 17.1 & 26.6 & 35.3 & 44.0 & 54.1 \\
\hline
\end{tabular}

\footnotetext{
$* 1$ : Soybean oil: pollock liver oil $=3: 2$.

*2: Ogino's salt mixture. ${ }^{\text {(1) }}$

${ }^{* 3}$ : Same as previously reported. ${ }^{7}$
} 
as the sole source of dietary protein. Amino acid composition of these protein sources was determined by an automatic amino acid analyzer (Hitachi model 835) after hydrolysis by $6 \mathrm{~N} \mathrm{HCl}$, and $10 \mathrm{~N} \mathrm{Ba}(\mathrm{OH})_{2}$ for ordinary amino acids and tryptophan, respectively, ${ }^{8}$ Cyst(e)ine content was determined from cysteic acid after performic acid treatment. ${ }^{8)}$ The total sulfur amino acid (methionine plus cystine) content in casein is about half of that in egg white albumin (Table 2). Twelve experimental diets containing $10,20,30,40,50$, and $60 \%$ of the respective protein sources were prepared. The experimental diets were formed into pellets and freeze-dried. Crude protein content in the diets was measured by the Kjeldahl methods using a KJELTEC AuTo 1030 analyzer.

\section{Fish and Feeding}

Fingerling rainbow trout Oncorhynchus mykiss of the Nikko strain obtained from the Nikko branch of the National Research Institute of Aquaculture were used for this study. For acclimatization to a purified diet, they were fed a $50 \%$ casein diet for two weeks before starting the feeding experiment. Fish having a mean body weight of about $17 \mathrm{~g}$ were divided into 12 experimental groups of 18 fish each. Each group of fish was kept in a separate $20 /$ glass tank, and the water temperature was kept at $15^{\circ} \mathrm{C}$ throughout the feeding experiment. The fish were fed the experimental diets to satiation 4 times daily for 10 days. Eighteen hours after the final feeding, five fish were taken out from each tank and anesthetized with $0.01 \%$ ethyl 3-aminobenzoate, methanesulfonic acid. The liver was immediately excised, rinsed with $0.9 \% \mathrm{NaCl}$ solution, and stored at $-70^{\circ} \mathrm{C}$ in a deep freezer until used for hepatic $\mathrm{CDO}$ activity assay. Another five fish from each dietary group fed egg white albumin diets were used to analyze the free amino acid contents in the liver and dorsal ordinary muscle.

\section{Assay of Hepatic Cysteine Dioxygenase Activity}

Each liver was homogenized with 9 volumes of $0.25 \mathrm{M}$ sucrose solution. The homogenate was centrifuged at $100,000 \times g$ for $60 \mathrm{~min}$ and the supernatant obtained was used for the enzyme assay. CDO activity was measured radiochemically by the method of Yamaguchi and Hosokawa ${ }^{1 /}$ using $L-\left[{ }^{35} \mathrm{~S}\right]$ cysteine as a substrate. Incubation was conducted in the presence of a sufficient amount of CDO-stabilizing protein obtained from rat liver extract. ${ }^{5,9)}$ The assay mixture was first incubated anaerobically at $37^{\circ} \mathrm{C}$ for $40 \mathrm{~min}$ to activate the enzyme. Further incubation was carried out for $15 \mathrm{~min}$ at $37^{\circ} \mathrm{C}$ shaking at 120 strokes/min under aerobic conditions. One unit of enzyme activity was defined as the amount of enzyme producing

Table 2. Amino acid composition of protein source for experimental diets

$\mathrm{mg} / \mathrm{g}$ protein $)^{*}$

\begin{tabular}{lcr}
\hline \multicolumn{1}{c}{ Amino acid } & Egg white albumin & Casein \\
\hline Methionine & 39 & 29 \\
$1 / 2$ Cystine & 30 & 5 \\
Total sulfur amino acid & 69 & 34 \\
& & \\
Alanine & 74 & 33 \\
Arginine & 58 & 38 \\
Aspartic acid & 99 & 70 \\
Glutamic acid & 158 & 268 \\
Glycine & 37 & 19 \\
Histidine & 25 & 29 \\
Isoleucine & 55 & 56 \\
Leucine & 90 & 100 \\
Lysine & 72 & 88 \\
Phenylalanine & 64 & 55 \\
Proline & 38 & 127 \\
Serine & 78 & 66 \\
Threonine & 50 & 48 \\
Tryptophan & 15 & 14 \\
Tyrosine & 47 & 67 \\
Valine & 72 & 69 \\
& &
\end{tabular}

* The values were obtained by using automatic amino acid analyzer (Hitachi model 835). Almost of amino acids were analyzed after hydrolyzing with $6 \mathrm{~N}$ $\mathrm{HCl}$ for $24 \mathrm{~h}$. Cystine was determined as cysteic acid after oxidation with performic acid. Tryptophan was determined after alkaline hydrolization.
$1 \mu$ mole of cysteine sulfinate in $1 \mathrm{~h}$ at $37^{\circ} \mathrm{C}$. Specific activity is expressed as the unit of enzyme activity per $\mathrm{mg}$ of protein. Protein content in the enzyme preparation was determined by the method of Lowry et al. ${ }^{10)}$ with bovine serum albumin as a standard.

\section{Free Amino Acid Analysis}

The tissue samples of five fish fed the egg white albumin diet were separately homogenized with 4 volumes of $10 \%$ trichloroacetic acid. The homogenate was centrifuged to remove denatured protein. The aqueous layer was used for the quantitative analysis of free amino acids. Amino acids except cysteine were analyzed using an automatic amino acid analyzer (Hitachi model 835) as reported previously. ${ }^{11}$ Cysteine was determined by the colorimetric method of Gaitonde ${ }^{12)}$ using acidic ninhydrin reagent.

\section{Results}

Growth of Fish

The body weight gains of rainbow trout fed the experimental diets are shown in Fig. 1. During the 10 day feeding period, the fish fed Diet 5 (50\% egg albumin, crude protein content $42.6 \%$ ) achieved approximately a $50 \%$ weight gain which was 3 times higher than that of the fish fed Diet $1(10 \%$ egg albumin, crude protein content $8.6 \%)$ Further increases in protein level did not improve the growth rate. A similar trend in growth was observed also in the fish fed the casein diets (Diets 7 to 12). However, the maximum growth rate obtained by feeding the casein diets was somewhat lower than the maximum growth rate

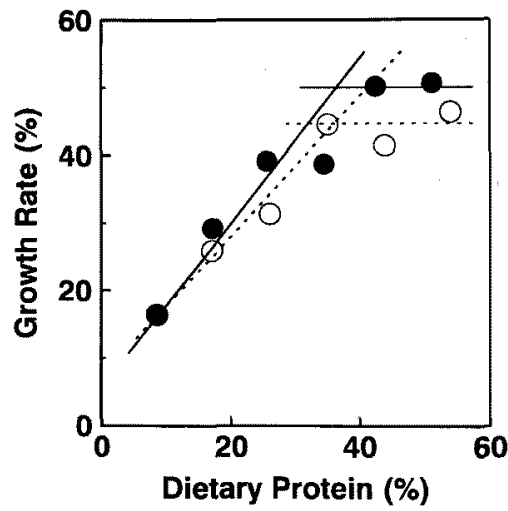

Fig. 1. Effect of dietary protein levels on percent weight gain of rainbow trout.

: Egg white albumin diets, $\mathrm{O}$ : casein diets.

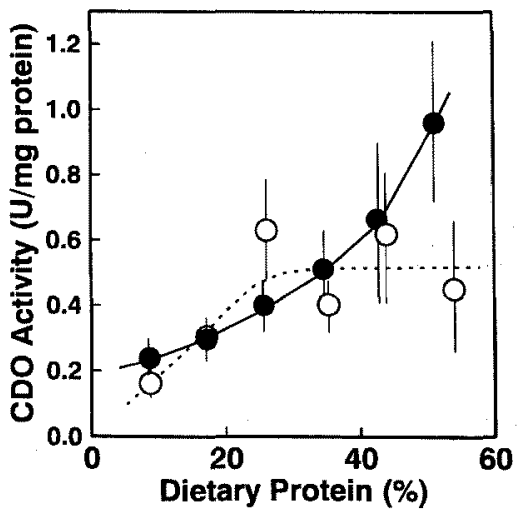

Fig. 2. Effect of dietary protein levels on hepatic cystein dioxygenase (CDO) activity of rainbow trout.

Values are means \pm standard deviation of five fish. 0 : Egg white albumin diets, $O$ : casein diets. 
Table 3. Hepatic amino acid concentrations ( $\mu \mathrm{mol} / \mathrm{g}$ tissue) of rainbow trout fed diets differing in protein levels by employing egg white albumin as a sole protein source

\begin{tabular}{|c|c|c|c|c|c|c|}
\hline & \multicolumn{6}{|c|}{ Diet number } \\
\hline & 1 & 2 & 3 & 4 & 5 & 6 \\
\hline \multicolumn{7}{|l|}{ Amino acid*1 } \\
\hline Taurine & $6.46 \pm 1.74$ & $14.93 \pm 4.53$ & $20.19 \pm 2.71$ & $19.58 \pm 1.49$ & $18.91 \pm 3.93$ & $18.43 \pm 2.43$ \\
\hline Aspartate & $0.36 \pm 0.04$ & $0.53 \pm 0.14$ & $1.04 \pm 0.20$ & $1.15 \pm 0.34$ & $1.56 \pm 0.19$ & $1.00 \pm 0.19$ \\
\hline Hydroxyproline & $0.11 \pm 0.07$ & $0.09 \pm 0.08$ & $0.08 \pm 0.08$ & $0.12 \pm 0.07$ & $0.12 \pm 0.07$ & $0.13 \pm 0.02$ \\
\hline Threonine & $0.31 \pm 0.04$ & $0.42 \pm 0.09$ & $0.59 \pm 0.06$ & $0.76 \pm 0.09$ & $1.17 \pm 0.25$ & $1.36 \pm 0.11$ \\
\hline Serine & $0.51 \pm 0.07$ & $0.51 \pm 0.07$ & $0.61 \pm 0.13$ & $1.07 \pm 0.12$ & $1.58 \pm 0.31$ & $1.52 \pm 0.28$ \\
\hline Glutamate & $3.50 \pm 1.69$ & $4.72 \pm 0.55$ & $6.81 \pm 0.69$ & $6.07 \pm 0.91$ & $3.86 \pm 0.31$ & $4.10 \pm 0.96$ \\
\hline Proline & $0.22 \pm 0.03$ & $0.26 \pm 0.05$ & $0.34 \pm 0.06$ & $0.43 \pm 0.09$ & $0.77 \pm 0.18$ & $0.69 \pm 0.14$ \\
\hline Glycine & $1.70 \pm 0.15$ & $2.00 \pm 0.24$ & $1.80 \pm 0.28$ & $2.22 \pm 0.26$ & $3.09 \pm 0.42$ & $3.15 \pm 0.31$ \\
\hline Alanine & $2.84 \pm 0.63$ & $4.27 \pm 0.73$ & $6.15 \pm 0.41$ & $6.07 \pm 0.47$ & $6.88 \pm 1.30$ & $6.21 \pm 0.42$ \\
\hline Valine & $0.44 \pm 0.07$ & $0.49 \pm 0.11$ & $0.75 \pm 0.11$ & $1.13 \pm 0.13$ & $1.48 \pm 0.27$ & $1.35 \pm 0.02$ \\
\hline Cysteine & $0.69 \pm 0.05$ & $0.64 \pm 0.10$ & $0.59 \pm 0.10$ & $0.66 \pm 0.08$ & $0.79 \pm 0.08$ & $0.72 \pm 0.05$ \\
\hline Cystine & $\mathrm{ND}^{* 2}$ & $\mathrm{ND}$ & ND & ND & $\overline{N D}$ & ND \\
\hline Methionine & $0.16 \pm 0.02$ & $0.14 \pm 0.03$ & $0.15 \pm 0.04$ & $0.20 \pm 0.05$ & $0.50 \pm 0.13$ & $0.47 \pm 0.13$ \\
\hline Cystathionine & $0.03 \pm 0.01$ & $0.06 \pm 0.04$ & $0.09 \pm 0.01$ & $0.20 \pm 0.02$ & $0.60 \pm 0.31$ & $0.61 \pm 0.28$ \\
\hline Isoleucine & $0.20 \pm 0.04$ & $0.19 \pm 0.02$ & $0.26 \pm 0.04$ & $0.40 \pm 0.07$ & $0.65 \pm 0.18$ & $0.53 \pm 0.05$ \\
\hline Leucine & $0.45 \pm 0.09$ & $0.43 \pm 0.04$ & $0.54 \pm 0.07$ & $0.80 \pm 0.12$ & $1.26 \pm 0.32$ & $1.03 \pm 0.09$ \\
\hline Tyrosine & $0.18 \pm 0.03$ & $0.22 \pm 0.05$ & $0.29 \pm 0.06$ & $0.33 \pm 0.06$ & $0.47 \pm 0.11$ & $0.37 \pm 0.04$ \\
\hline Phenylalanine & $0.33 \pm 0.06$ & $0.32 \pm 0.05$ & $0.39 \pm 0.08$ & $0.46 \pm 0.07$ & $0.61 \pm 0.11$ & $0.54 \pm 0.05$ \\
\hline Ammonium & $2.20 \pm 0.23$ & $2.34 \pm 0.19$ & $2.94 \pm 0.11$ & $3.38 \pm 0.17$ & $4.12 \pm 0.21$ & $3.88 \pm 0.30$ \\
\hline Ornithine & $0.06 \pm 0.03$ & $0.08 \pm 0.04$ & $0.10 \pm 0.03$ & $0.17 \pm 0.05$ & $0.29 \pm 0.14$ & $0.41 \pm 0.08$ \\
\hline Tryptophan & $0.06 \pm 0.04$ & $0.10 \pm 0.03$ & $0.10 \pm 0.02$ & $0.15 \pm 0.04$ & $0.22 \pm 0.04$ & $0.15 \pm 0.02$ \\
\hline Lysine & $0.38 \pm 0.07$ & $0.40 \pm 0.05$ & $0.59 \pm 0.10$ & $0.84 \pm 0.09$ & $1.27 \pm 0.27$ & $1.17 \pm 0.07$ \\
\hline Histidine & $0.83 \pm 0.04$ & $1.11 \pm 0.09$ & $1.22 \pm 0.09$ & $1.24 \pm 0.10$ & $1.25 \pm 0.07$ & $1.16 \pm 0.04$ \\
\hline Arginine & $0.26 \pm 0.08$ & $0.21 \pm 0.03$ & $0.33 \pm 0.05$ & $0.41 \pm 0.04$ & $0.48 \pm 0.09$ & $0.29 \pm 0.08$ \\
\hline
\end{tabular}

*1: Values are means of five individual measurements \pm standard deviation.

*2: ND: Not detected.

Table 4. Muscular amino acid concentrations ( $\mu \mathrm{mol} / \mathrm{g}$ tissue) of rainbow trout fed diets differing in protein levels by employing egg white albumin as a sole protein source

Diet number

\begin{tabular}{lllllll}
\hline 1 & 2 & 3 & 4 & 5 & 6
\end{tabular}

\begin{tabular}{|c|c|c|c|c|c|c|}
\hline \multicolumn{7}{|l|}{ Amino acid*1 } \\
\hline Taurine & $1.08 \pm 0.22$ & $1.27 \pm 0.09$ & $1.98 \pm 0.58$ & $1.95 \pm 0.59$ & $3.88 \pm 0.59$ & $3.95 \pm 0.81$ \\
\hline Aspartate & $0.04 \pm 0.02$ & $0.09 \pm 0.08$ & $0.35 \pm 0.31$ & $0.30 \pm 0.39$ & $0.71 \pm 0.25$ & $0.65 \pm 0.39$ \\
\hline Hydroxyproline & $0.99 \pm 0.33$ & $1.61 \pm 0.21$ & $1.25 \pm 0.28$ & $0.70 \pm 0.24$ & $0.57 \pm 0.13$ & $0.53 \pm 0.14$ \\
\hline Threonine & $0.43 \pm 0.12$ & $0.45 \pm 0.08$ & $0.90 \pm 0.16$ & $0.98 \pm 0.33$ & $1.87 \pm 0.62$ & $1.98 \pm 0.53$ \\
\hline Serine & $1.59 \pm 0.27$ & $2.03 \pm 0.34$ & $3.20 \pm 0.56$ & $2.14 \pm 0.45$ & $1.16 \pm 0.52$ & $1.41 \pm 0.34$ \\
\hline Glutamate & $0.75 \pm 1.03$ & $0.39 \pm 0.12$ & $0.75 \pm 0.19$ & $0.74 \pm 0.17$ & $1.24 \pm 0.24$ & $1.24 \pm 0.27$ \\
\hline Proline & $0.01 \pm 0.03$ & $0.03 \pm 0.04$ & $0.08 \pm 0.05$ & $0.12 \pm 0.03$ & $0.36 \pm 0.10$ & $0.26 \pm 0.08$ \\
\hline Glycine & $20.21 \pm 3.29$ & $22.87 \pm 1.17$ & $19.33 \pm 3.51$ & $21.88 \pm 4.48$ & $18.85 \pm 3.25$ & $19.28 \pm 2.85$ \\
\hline Alanine & $4.97 \pm 1.31$ & $4.80 \pm 1.18$ & $4.19 \pm 1.56$ & $3.69 \pm 0.58$ & $5.24 \pm 0.56$ & $4.71 \pm 0.40$ \\
\hline Valine & $0.26 \pm 0.08$ & $0.24 \pm 0.04$ & $0.31 \pm 0.06$ & $0.40 \pm 0.08$ & $0.64 \pm 0.13$ & $0.62 \pm 0.08$ \\
\hline Cysteine & $0.04 \pm 0.01$ & $0.07 \pm 0.02$ & $0.09 \pm 0.01$ & $0.10 \pm 0.01$ & $0.13 \pm 0.01$ & $0.13 \pm 0.02$ \\
\hline Cystine & $\mathrm{ND}^{* 2}$ & ND & ND & ND & ND & ND \\
\hline Methionine & $0.08 \pm 0.01$ & $0.09 \pm 0.05$ & $0.10 \pm 0.05$ & $0.11 \pm 0.02$ & $0.36 \pm 0.22$ & $0.38 \pm 0.25$ \\
\hline Cystathionine & $0.05 \pm 0.04$ & $0.36 \pm 0.16$ & $0.54 \pm 0.10$ & $0.53 \pm 0.14$ & $1.02 \pm 0.22$ & $0.96 \pm 0.10$ \\
\hline Isoleucine & $0.08 \pm 0.03$ & $0.06 \pm 0.01$ & $0.09 \pm 0.01$ & $0.12 \pm 0.02$ & $0.20 \pm 0.05$ & $0.18 \pm 0.04$ \\
\hline Leucine & $0.12+0.04$ & $0.11 \pm 0.02$ & $0.15 \pm 0.01$ & $0.20 \pm 0.03$ & $0.36 \pm 0.08$ & $0.34 \pm 0.06$ \\
\hline Tyrosine & $0.06 \pm 0.01$ & $0.12 \pm 0.05$ & $0.12 \pm 0.04$ & $0.10 \pm 0.03$ & $0.10 \pm 0.03$ & $0.08 \pm 0.03$ \\
\hline Phenylalanine & $0.16 \pm 0.01$ & $0.21 \pm 0.03$ & $0.21 \pm 0.03$ & $0.20 \pm 0.01$ & $0.25 \pm 0.03$ & $0.24 \pm 0.04$ \\
\hline Ammonium & $8.52 \pm 0.18$ & $8.90 \pm 0.45$ & $10.36 \pm 0.46$ & $11.94 \pm 1.13$ & $12.75 \pm 0.85$ & $13.87 \pm 0.75$ \\
\hline Ornithine & $0.00 \pm 0.01$ & $0.00 \pm 0.00$ & $0.02 \pm 0.01$ & $0.03 \pm 0.01$ & $0.03 \pm 0.01$ & $0.05 \pm 0.02$ \\
\hline Tryptophan & $0.01 \pm 0.01$ & $0.04 \pm 0.01$ & $0.01 \pm 0.02$ & $0.00 \pm 0.00$ & $0.04 \pm 0.03$ & $0.06 \pm 0.02$ \\
\hline Lysine & $0.07 \pm 0.08$ & $0.03 \pm 0.01$ & $0.09 \pm 0.04$ & $0.12 \pm 0.07$ & $0.21 \pm 0.05$ & $0.29 \pm 0.19$ \\
\hline Histidine & $9.20 \pm 0.96$ & $7.45 \pm 1.15$ & $6.92 \pm 0.36$ & $7.84 \pm 1.48$ & $6.16 \pm 1.02$ & $6.76 \pm 0.79$ \\
\hline Arginine & $0.00 \pm 0.01$ & $0.01 \pm 0.01$ & $0.01 \pm 0.01$ & $0.02 \pm 0.01$ & $0.03 \pm 0.00$ & $0.03 \pm 0.01$ \\
\hline
\end{tabular}

*1: Values are means of five individual measurements \pm standard deviation.

*2: ND: Not detected. 
obtained in fish fed the albumin diets.

\section{Hepatic Cysteine Dioxygenase Activity}

As shown in Fig. 2, the specific activity of CDO in the liver of rainbow trout fed egg white albumin diets increased exponentially from $0.2 \mathrm{U} / \mathrm{mg}$ protein to $0.9 \mathrm{U} / \mathrm{mg}$ protein as dietary protein level increased up to $51 \%$. Also, the CDO activity in the dietary groups of casein increased as the dietary protein level increased up to $26 \%$. However further increases in casein level failed to enhance its activity (Diets 10 to 12 ).

\section{Free Amino Acid Concentrations in Tissues}

The concentrations of certain free amino acids including taurine in the liver and muscle of the fish fed egg white albumin diets are listed in Tables 3 and 4, respectively. The concentrations of most essential amino acids in these tissues tended to increase as the dietary albumin level increased. These values in the livers of the fish fed Diets 1 to 4 remained relatively low, but increased 2-3 times in the fish fed Diets 4 and 5. Muscular methionine concentration was also influenced by dietary protein level in a similar manner to the hepatic concentration. In both liver and muscle, the concentration of cystathionine, an intermediate product in the transsulfuration pathway from methionine to cysteine, rose as dietary protein level increased. The highest values which were obtained in the liver and muscle of the fish fed Diets 5 and 6 were twenty times higher than those of the fish fed Diet 1. A relatively high level of cystathionine was accumulated even in the muscle of the fish fed Diet 2 having only $17 \%$ protein. The hepatic taurine concentration tripled as dietary protein level increased from 9 to $26 \%$. However, the concentration did not increase in the fish fed the diets containing more than $35 \%$ protein. Also, the muscular taurine concentration increased as dietary protein level increased in a similar manner to that of the hepatic concentration.

\section{Discussion}

CDO is considered to play an important role in regulating sulfur amino acid metabolism involving taurine biosynthesis in mammals. ${ }^{3)}$ Hosokawa et al. ${ }^{4)}$ observed that the hepatic CDO activity of rats fed casein or soy protein diet was boosted by supplementing methionine which is the first limiting amino acid of these protein sources, and the activity decreased conversely by supplementing the first limiting amino acid, lysine to wheat gluten diet. Thus, they claim that the hepatic CDO activity can be used as a sensitive indicator of the nutritive value of dietary protein for rats. Recently, we found much higher activity of CDO in the liver of rainbow trout than that in the other tissues such as the brain, heart, kidney, and muscle, and only the hepatic activity was enhanced further by feeding L-methionine or L-cystine supplemented casein diets. ${ }^{5)}$ In the present study, the specific activity of CDO in the liver of rainbow trout increased as the level of egg white albumin increased. However, the CDO activity of the fish fed the casein diets remained low, and a somewhat lower maximum growth rate was obtained than those fed the egg albumin diet. Egg white albumin used in the present study had almost twice the total sulfur amino acid content than the casein. Moreover, casein contained a small amount of cyst(e)ine (Table 2). The exponential increase in activity of hepatic CDO found in rainbow trout fed the egg albumin diets may have resulted from the rise in dietary levels of sulfur amino acids especially cyst(e)ine rather than protein level per se. Possibly, the induced hepatic CDO activity due to the presence of excess dietary sulfur amino acids stimulated catabolism of cysteine to taurine which accumulated in the liver and muscle up to a certain level before being excreted. Thus the hepatic CDO may be involved in the regulating sulfur amino acid metabolism, and the hepatic CDO activity may reflect the amino acid balance of dietary protein in fish as well.

Although the hepatic CDO activity of rainbow trout is induced by either $1 \%$ methionine or $1 \%$ cystine supplementation to a $40 \%$ casein diet, ${ }^{5)}$ it has not been demonstrated that methionine itself can boost directly the activity of CDO in rainbow trout. Methionine is possibly catabolized to cysteine through the biological transsulfuration pathway in rainbow trout. ${ }^{13,14)}$ In this study, however, cystathionine was accumulated in rainbow trout when they were fed the diets containing over $50 \%$ egg white albumin. Similar accumulation was also found in the rainbow trout fed excess methionine but was not found in those fed excess cystine. ${ }^{11)}$ In the former case, the fish excreted small amounts of taurine, but high amounts of taurine in the latter case. Cystathionine is one of the important intermediates in the transsulfuration pathway from methionine to cysteine and this compound is the last precursor of cysteine formation in animals. ${ }^{15)}$ It is evident that transsulfuration does not work effectively in rainbow trout fed a dietary excess of methionine. It is apparent that a considerable quantity of taurine is synthesized from dietary methionine also in rainbow trout, ${ }^{11,13,14)}$ but there is a certain characteristic inhibition in the metabolic pathway from cystathionine to cysteine in rainbow trout.

\section{References}

1) K. Yamaguchi and Y. Hosokawa: Cysteine dioxygenase, in "Methods in Enzymology" (ed. by W. B. Jakoby and O. W. Griffith), Vol. 143 Academic Press, New York, 1987, pp. 395 403.

2) K. Yamaguchi: Nutrition and metabolism of sulfur amino acids, in "Nutrition: Proteins and Amino Acids" (ed. by A. Yoshida, H. Naito, Y. Niiyama, and T. Suzuki), Japan Sci. Soc. Press, Tokyo/Springer, Berlin, 1990, pp. 165-183.

3) N. Kohashi, K. Yamaguchi, Y. Hosokawa, Y. Kori, O. Fujii, and I. Ueda: Dietary control of cysteine dioxygenase in rat liver. $J$. Biochem., 81, 159-168 (1978).

4) Y. Hosokawa, S. Niizeki, H. Tojo, I. Sato, and K. Yamaguchi Hepatic cysteine dioxygenase activity and sulfur amino acid metabolism in rats: Possible indicators in the evaluation of protein quality. $J$. Nutr., 118, 456-461 (1988)

5) M. Yokoyama and J. Nakazoe: Induction of cysteine dioxygenase activity in rainbow trout liver by dietary sulfur amino acids. Proc. Third Int. Symp. on Feeding and Nutr. in Fish, Toba, Aug. 28-Sept. 1., Japan, 1989, pp. 367-372.

6) C. Ogino, L. Takeuchi, H. Takeda, and T. Watanabe: Availability of dietary phosphorus in carp and rainbow trout. Nippon Suisan Gakkaishi, 45, 1527-1532 (1979).

7) M. Yokoyama and J. Nakazoe: Effects of dietary protein levels on free amino acid and glutathione contents in the tissues of rainbow trout. Comp. Biochem. Physiol., 99A, 203-206 (1991).

8) Resources Council: Standard Tables of Food Composition in Japan, Amino Acid Composition of Foods, Revised edition, Science and Technology Agency, Japan, 1986, 181 pp. 
9) K. Yamaguchi and $Y$. Hosokawa: The stabilizing protein, protein-A of cysteine dioxygenase, in "The Biology of Taureine: Methods and Mechanisms" (ed. by R. J. Huxtable, F. Franconi, and A. Gotti) Plenum Press, New York, 1987, pp. 29-38.

10) O. H. Lowry, N. J. Rosebrough, A. L. Farr, and R. J. Randall: Protein measurement with the Folin phenol reagent. $J$. Biol. Chem., 193, 265-275 (1951).

11) M. Yokoyama and J. Nakazoe: Accumulation and excretion of taurine in rainbow trout fed diets supplemented with methionine, cystine, and taurine. Comp. Biochem. Physiol., 102A, 565-568(1992).

12) M. K. Gaitonde: A spectrophotometric method for the direct determination of cysteine in the presence of other naturally occurring amino acids. Biochem. J., 104, 627-633 (1967).

13) M. J. Walton, C. B. Cowey, and J. W. Adron: Methionine metabolism in rainbow trout fed diets of differing methionine and cystine content. J. Nutr., 112, 1525-1535 (1982).

14) C. B. Cowey, C. Y. Cho, J. G. Sivak, J. A. Weerheim, and D. D. Stuart: Methionine intake in rainbow trout (Oncorhynchus mykiss), relation to cataract formation and the metabolism of methionine. $J$. Nutr., 122, 1154-1163 (1992).

15) $O$. W. Griffith: Mammalian sulfur amino acid metabolism; an overview, in "Methods in Enzymology" (ed. by W. B. Jakoby and O. W. Griffith), Vol. 143, Academic Press, New York, 1987, pp. 366-376. 